\title{
Palladium-Catalyzed Desulfitative Mizoroki-Heck Coupling Reactions of Sul- fonyl Chlorides with Olefins in a Nitrile-functionalized Ionic Liquid.
}

\author{
Srinivas Reddy Dubbaka, ${ }^{\mathrm{a}}$ Dongbin Zhao, ${ }^{\mathrm{b}}$ Zhaofu Fei, ${ }^{\mathrm{b}}$ Chandra M. Rao Volla, ${ }^{\mathrm{a}}$ Paul J. Dyson*b ${ }^{* \mathrm{~b}}$ Pierre Vogel ${ }^{* \mathrm{a}}$
}

${ }^{a}$ Laboratory of Glycochemistry and Asymmetric Synthesis, ${ }^{b}$ Laboratory of Organometallic and Medicinal Chemistry

Swiss Federal Institute of Technology (EPFL), BCH CH-1015 Lausanne (Switzerland)

Fax: +41.21.6939375; E-mail: pierre.vogel@epfl.ch

\begin{abstract}
In our previous paper (Chem. Eur. J. 2005, 11, 2633), we have shown that aryl and alkenyl sulfonyl chlorides can be used in Heck-Mizoroki-type couplings with mono- and disubustituted olefins in the presence of palla$\operatorname{dium}(0)$ or rhodium(I) catalysts. Here we show that these reactions can be conducted more effectively in a nitrile functionalized ionic liquid, viz. $\left[\mathrm{C}_{3} \mathrm{CNmim}\right]\left[\mathrm{Tf}_{2} \mathrm{~N}\right]$. Advantages include; (1) use of a cheap catalyst source, $\mathrm{PdCl}_{2},(2)$ ability to handle the catalyst in air, (3) reduced reaction times, (4) elimination of phase transfer catalysts due to the high solubility of the inorganic base in the ionic liquid, and (5) facile recycling of the ionic liquid-palladium catalyst. The yields of coupling products remain in the same range as the reactions conduced in organic solvents. Palladium nanoparticles have been identified in the ionic liquid following the Heck-Mizoroki type coupling reactions which were characterized using transmission electron microscopy (TEM).
\end{abstract}

Key Words: Mizoroki-Heck reaction, Ionic liquids, Palladium, Sulfonyl chlorides, Nanoparticles.

Transition metal catalyzed C-C bond forming reactions are among the most useful and versatile methods in organic synthesis. ${ }^{1,2}$ In recent years, various methodologies have been developed, such as Mizoroki-Heck protocol, that permit the cross-coupling of a large variety of reactants (Scheme 1). ${ }^{2}$

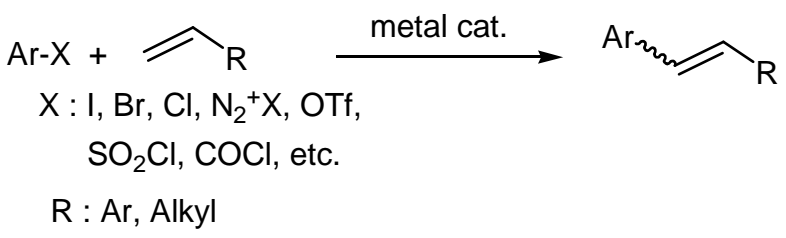

Scheme 1: Substrates for general Mizoroki-Heck-type reactions

The Mizoroki-Heck arylation of alkenes is of high synthetic utility, ${ }^{1,2}$ and aryl chlorides and alkenes can be coupled under decarbonylative conditions. ${ }^{3}$ We have shown that the readily available sulfonyl chlorides ( $\mathrm{RSO}_{2} \mathrm{Cl}, \mathrm{R}=$ aryl, alkenyl, methallyl, ${ }^{4}$ benzyl) undergo desulfitative Stille and carbonylative Stille, ${ }^{5}$ SuzukiMiyaura, ${ }^{6}$ Sonogashira-Hagihara ${ }^{7}$ and Negishi ${ }^{8}$ crosscoupling reactions and Mizoroki-Heck arylations. ${ }^{9}$ The sulfonyl chlorides are generally more reactive than corresponding bromides and chlorides. ${ }^{7,8,10}$ As far as we are aware, ionic liquids (ILs) have not been used in transi- tion metal catalyzed reactions using sulfonyl chlorides as reactants.

In the last few years ionic liquids have proven to be highly useful solvents in catalysis and also in organic synthesis. ${ }^{11}$ There are several reports on Stille, ${ }^{12}$ SuzukiMiyaura, ${ }^{13}$ Sonogashira-Hagihara, ${ }^{14}$ cross-coupling reactions and regioselective Heck arylations ${ }^{15}$ with aryl halides under ionic liquids. Various benefits have been noted including; (i) assists in the activation of the catalyst; (ii) improvement the stability of the catalyst; (iii) excellent immobilisation and recyclability; (iv) facilitate product isolation and (v) influence on the selectivity of the reaction.

Following our previous studies that have shown nitrile functionalized ionic liquids to be highly effective solvents for conducting various $\mathrm{C}-\mathrm{C}$ cross coupling reactions, ${ }^{16}$ we selected $N$-butyronitrile pyridinium bis(trifluoromethylsulfonyl)-imide (IL 1, Scheme 2) for the reactions described herein together with $\mathrm{PdCl}_{2}$ (1 $\mathrm{mol} \%$ ), as the pre-catalyst since it can be handled in air and is comparatively cheap (this pre-catalyst, in IL $\mathbf{1}$ was as active as Herrmann's catalyst ${ }^{17}$ in organic solvent, see below). Dissolution of $\mathrm{PdCl}_{2}$ in IL 1 results in the formation of the complex shown in Scheme 2.

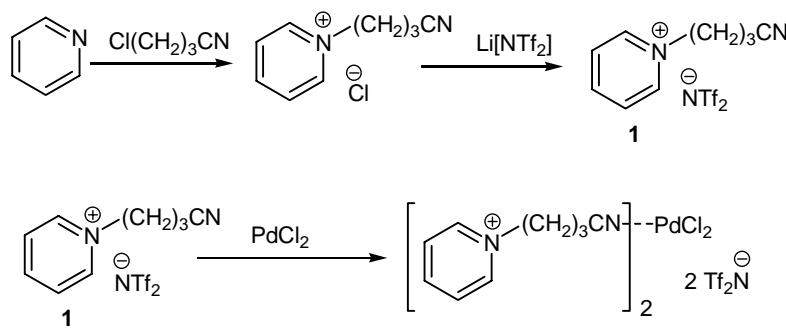

Scheme 2: Synthesis of $N$-butyronitrile pyridinum and their palladium complex.

Our exploratory experiments started with the coupling of 1-naphthalenesulfonyl chloride $(1.5 \mathrm{mmol})$ with butyl acrylate $(3.5 \mathrm{mmol})$ in the presence of $\mathrm{PdCl}_{2}(1$ $\mathrm{mol} \%), \mathrm{Me}(\text { oct })_{3} \mathrm{NCl}(15 \mathrm{~mol} \%)$, and $\mathrm{K}_{2} \mathrm{CO}_{3}(2.25$ $\mathrm{mmol})$ in IL 1 (2 mL). All materials were handled in air although the reaction was subsequently conducted under a blanket of nitrogen. After $1.5 \mathrm{~h}$ at $140^{\circ} \mathrm{C}$ (cf. $4 \mathrm{~h}$ to achieve the same conversion in $m$-xylene in the presence of a phase transfer agent) ${ }^{9}$ the coupling product was extracted from IL 1 using diethyl ether. Starting material was not detected in the extract and the yield of the product $(90 \%)$ was estimated by GC using an external standard. The IL was re-charged with starting materials (as 
above) and after $2 \mathrm{~h}$ at $140^{\circ} \mathrm{C}$ the product was isolated in $85 \%$ yield following extraction into diethyl ether. IL 1 was charged with further starting materials (third batch) and the reaction was repeated with only a slight decrease in catalytic activity.

The same reaction was conducted in the absence of $\mathrm{Me}(\mathrm{oct})_{3} \mathrm{NCl}$ which resulted in the same catalytic activity.

Using these optimized conditions the desulfitative coupling of electron-rich, electron-neutral and electronpoor sulfonyl chlorides with various olefins was conducted, see Table 1. We also prepared a 1,3-diene in the reaction of trans- $\beta$-styrenesulfonyl chloride with styrene under these conditions (Entry 10).

Table 1: Palladium-catalyzed desulfitative MizorokiHeck-type reactions of various sulfonyl chlorides with terminal alkenes in IL $\mathbf{1}$.

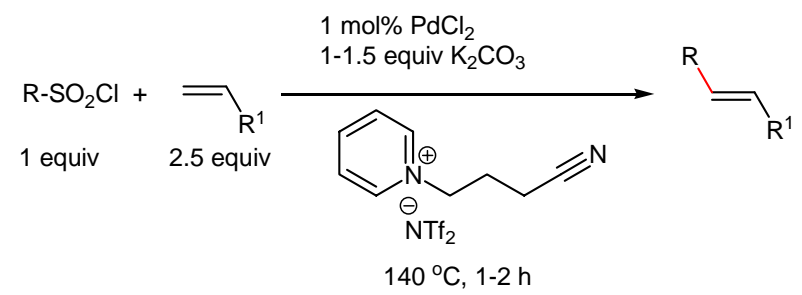

\begin{tabular}{cccc}
\hline Entry & $\mathrm{R}$ & $\mathrm{R}^{\mathrm{1}}$ & Yield $^{\mathrm{a}}$ \\
\hline 1 & 1-naphthyl & $\mathrm{COOnBu}$ & 90 \\
2 & 1-naphthyl & $\mathrm{Ph}$ & 80 \\
3 & 4-methylphenyl & $\mathrm{COOnBu}$ & 75 \\
4 & 4-methylphenyl & $\mathrm{Ph}$ & 80 \\
5 & 4-acetylphenyl & $\mathrm{COOnBu}$ & 70 \\
6 & 4-methoxyphenyl & $\mathrm{COOnBu}$ & $75^{\mathrm{b}}$ \\
7 & 3-cyanophenyl & $\mathrm{COOnBu}$ & $70^{\mathrm{b}}$ \\
8 & (4-trifluoromethyl)phenyl & $\mathrm{SO}{ }_{2} \mathrm{Ph}$ & $50^{\mathrm{b}}$ \\
9 & trifluoromethyl & $\mathrm{COOnBu}$ & $35^{\mathrm{c}}$ \\
10 & (E)-PhCH=CH & $\mathrm{Ph}$ & 90
\end{tabular}

${ }^{a}$ Yields of coupling products determined by GC using diphenylmethane as a external standard (see general procedure). ${ }^{\mathrm{b}}$ at $140{ }^{\circ} \mathrm{C}$ for $3 \mathrm{~h} .{ }^{\mathrm{c}}$ Using a microwave oven at $150{ }^{\circ} \mathrm{C}$ for $2 \mathrm{~h}$.

TEM analysis of the IL solutions after catalysis reveals that palladium nanoparticles were formed during the process (Fig. 1). Transition metal nanoparticles have been implicated as catalysts or catalyst reservoirs in many reactions in ILs and often they can be isolated and/or reused. ${ }^{18}$ The palladium nanoparticles isolated from IL 1 have a narrow size disparity (1.5 to $4.5 \mathrm{~nm}$ ), similar to those isolated following Stille C-C coupling reactions reported previously. ${ }^{16}$ As shown in Figure 1, three ILs employed in catalysis (entries 2, 5, and 7 from Table 1) were selected for TEM analysis. From the figure it is clear that the palladium nanoparticles are well dispersed and separated; nanoparticle aggregates are not observed. Nanoparticle aggregation during a catalytic process in ILs has been observed previously, ${ }^{19}$ but with the nitrile functionalized IL 1, no such detrimental effect was observed. TEM analysis of the ionic liquids taken after the first recyle shows that the palladium nanoparticles remain unchanged. It is not unreasonable to assume that the nitrile group on the IL provides a stabilizing effect. The EDX spectrum shows that nanoparticles are composed of palladium.
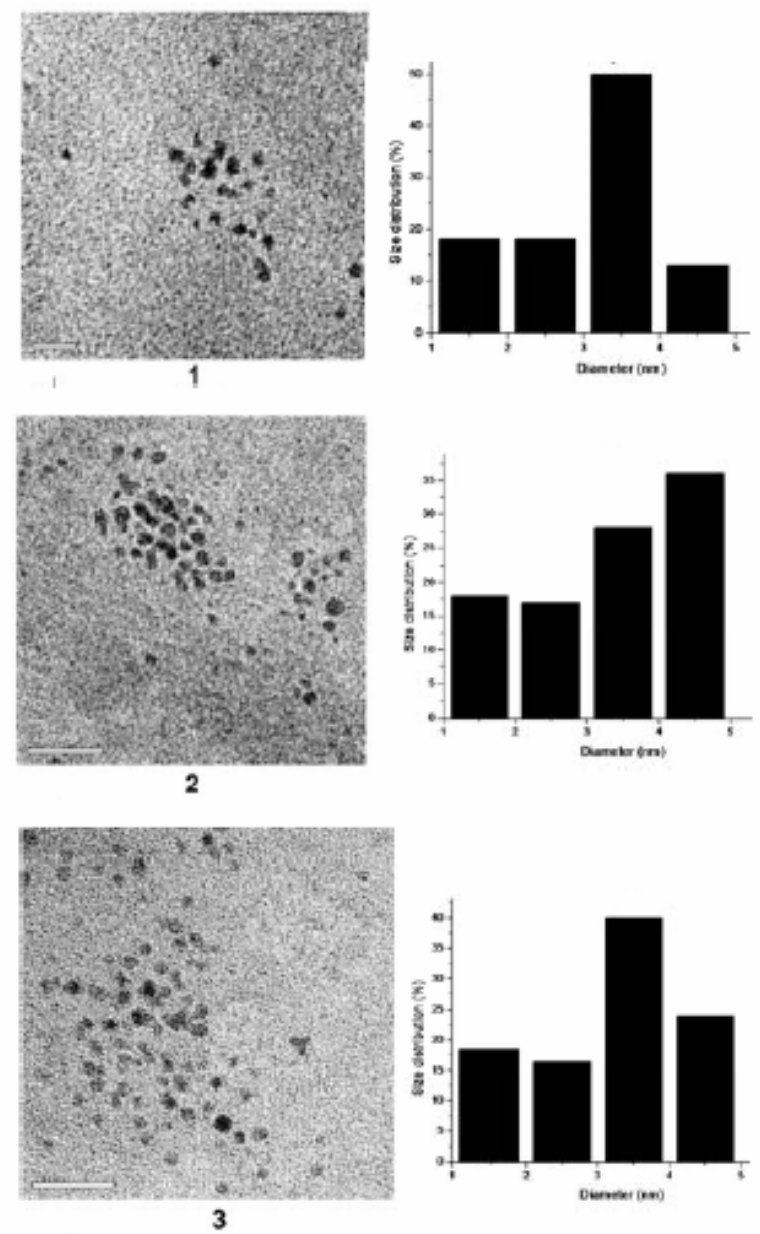

Figure 1. TEM images of nanopartcles in ionic liquids taken from catalytic system and graphs showing nanoparticle size distribution ( 1 for entry 7,2 for entry 5 , and $\mathbf{3}$ for entry 7).

In conclusion, we have demonstrated for the first time that desulfitative Mizoroki-Heck-type arylation of alkenes can be performed using sulfonyl chlorides in an IL. In addition, TEM analysis of nanoparticles extracted from the catalysis solution shows that palladium nanoparticles, which presumable act as catalyst reservoirs, are formed. It appears that a stabilizing effect on the nanoparticles is imparted by the nitrile-functionalised IL 1. Such task-specific ionic liquids may well prove to be decisive in transferring ionic liquids from the laboratory to production scale processes in $\mathrm{C}-\mathrm{C}$ bond forming reactions. The $\left[\mathrm{C}_{3} \mathrm{CNpy}\right]\left[\mathrm{Tf}_{2} \mathrm{~N}\right]$ ionic liquid described 
herein can be prepared from relatively inexpensive precursors, which provides further incentive for its deployment on a larger scale.

General procedure for desulfitative palladiumcatalyzed Mizoroki-Heck reaction of sulfonyl chlorides with monosubstituted olefins (refer to Table 1): To a Schlenk tube, the sulfonyl chloride (1 equiv, 1.5 mmol), $\mathrm{PdCl}_{2}$ ( $\left.1 \mathrm{~mol} \%, 0.015 \mathrm{mmol}\right), \mathrm{K}_{2} \mathrm{CO}_{3}$ (1.5 equiv, $2.25 \mathrm{mmol}), \mathrm{Me}(\mathrm{oct}){ }_{3} \mathrm{NCl}(15 \mathrm{~mol} \%, 0.23 \mathrm{mmol})$ and IL $1(2 \mathrm{~mL})$ were added. After the mixture was flushed with nitrogen, the olefin (2.0 equiv, $3.0 \mathrm{mmol})$ was added. The reaction mixture was heated at $140{ }^{\circ} \mathrm{C}$ for $1-2 \mathrm{~h}$. After cooling to room temperature, the product was extracted with diethyl ether $(3 \times 15 \mathrm{~mL})$. The combined extracts were washed with brine and water and then dried with $\mathrm{Na}_{2} \mathrm{SO}_{4}$. The coupling product was obtained after removal of solvent. An external standard (diphenylmethane, $0.6 \mathrm{mmol}$ ) was used for GC analysis. The ionic liquid phase was washed with diethyl ether and placed under vacuum of $18 \mathrm{~h}$ prior to the next catalytic cycle.

Acknowledgment. We thank the Swiss National Science Foundation (Grant 200020-108105) and the "Secrétariat d'Etat à l'Education et à la Recherche" (Grant SER No. 03.0738) for financial support.

\section{References and footnotes}

(1) (a) Mizoroki, T.: Mori, K.; Ozaki, A. Bull. Chem. Soc. Jpn. 1971, 44, 581. (b) Heck, R. F.; Nolley Jr, J. P. J. Org. Chem. 1972, 37, 2320-2322.

(2) For reviews of the Heck reaction, see, e. g: (a) Bräse, S.; de Meijere, A. In Metal-Catalyzed Cross-Coupling Reactions; F. Diederich, P. J., Stang, Eds.; Wiley: New York, 1998; Chapter 3. (b) Beletskaya, I. P.; Cheprakov, A. V. Chem. Rev. 2000, 100, 3009-3066. (c) Heck, R. F. In Comprehensive Organic Synthesis; Trost, B. M. Ed.; Pergamon: New York, 1991, Vol. 4, Chapter 4.3. (d) Heck, R F. Org. React. 1982, 27, 345-390. (e) Crisp, G. T. Chem. Soc. Rev. 1998, 27, 427-436; f) de Meijere, A.; Meyer, F. E. Angew. Chem. Int. Ed. Engl. 1994, 33, 2379-2411. (g) Jeffery, T. In Advances in Metal-Organic Chemistry; Liebeskind, L. S. Eds.; JAI: London, 1996; Vol. 5, pp 153-260. (h) Cabri, W.; Candiani, I. Acc. Chem. Res. 1995, 28, 2-7. (i) Littke, A. F.; Fu, G. C. Angew. Chem. Int. Ed. Engl. 2002, 41, 41764211. (j) Hassan, J.; Sévignon, M.; Gozzi, C.; Schulz, E. ; Lemaire, M. Chem. Rev. 2002, 102, 1359-1469. (k) Metal-Catalyzed Cross-Coupling Reactions; de Meijere, A.; Diederich, F. $2^{\text {nd }}$ Eds.; Wiley-VCH, Weinheim, 2004.

(3) Blaser, H.-U.; Spencer, A. J. Organomet. Chem. 1982, 233, 267-274.

(4) 2-Methylprop-2-enesulfonyl chloride preparation, see: (a) Bouchez, L. C.; Dubbaka, S. R.; Turks, M.; Vogel, P. J. Org. Chem. 2004, 69, 6413-6418. (b) Dubbaka, S. R.; Vogel, P. Tetrahedron 2005, 61, 1523-1530 and ref. cited therein.

Template for SYNLETT and SYNTHESIS $@$ Thieme Stuttgart $\cdot$ New York
(5) (a) Dubbaka, S. R.; Vogel, P. J. Am. Chem. Soc. 2003 125, 15292-15293. (b) Dubbaka, S. R.; Steunenberg, P.; Vogel, P. Synlett, 2004, 1235-1238.

(6) Dubbaka, S. R.; Vogel, P. Org. Lett. 2004, 6, 95-98.

(7) Dubbaka, S. R.; Vogel, P. Adv. Synth. Catal. 2004, 346, 1793-1797.

(8) Dubbaka, S. R.; Vogel, P. submitted to Chemical Communication.

(9) Dubbaka, S. R.; Vogel, P. Chem. Eur. J. 2005, 11, 26332641.

(10) For review, see: Dubbaka, S. R.; Vogel, P. Angew. Chem., Int. Ed. Engl. 2005, 44, 7674-7684.

(11) For recent review, see, for example: (a) Ionic Liquids as Green Solvents; Rogers, R. D., Seddon, K. R., Eds.; ACS Symposium Series 856; American Chemical Society: Washington, DC, 2003. (b) Ionic Liquids in Synthesis; Wasserscheid, P., Welton, T., Eds.; Wiley-VCH: Weinheim, 2003. (c) Rooney, D. W.; Seddon, K. R. In Handbook of Solvents; Wypych, G.; Ed.; ChemTech Publishing: Toronto, 2001, pp 1459-1484. (d) Seddon, K. R.; Stark, A.; Torres, M.-J. Pure Appl. Chem. 2000, 72, 2275-2287. (f) Wasserscheid, P.; Keim, W. Angew. Chem., Int. Ed. 2000, 39, 3772-3789. (e) Welton, T.; Smith, P. J. Adv. Organomet. Chem. 2004, 51, 251-284. (f) Dupont, J.; de Souza, R. F.; Suarez, P. A. Z. Chem. Rev. 2002, 102, 3667-3691. (g) Dyson, P. J.; Geldbach, T. Metal catalysed reactions in ionic liquids, Series: Catalysis by Metal Complexes, Springer, Vol. 29, 2005.

(12) (a) Chiappe, C.; Imperato, G.; Napolitano, E.; Pieraccini, D. Green Chem. 2004, 6, 33-36. (b) Handy, S. T.; Zhang, X. Org. Lett. 2001, 3, 233-236.

(13) (a) Mathews, C. J.; Smith, P. J.; Welton, T., Chem. Commun. 2000, 1249-1250. (b) Liu, S.; Fukuyama, T.; Sato, M.; Ryu, I. Synlett, 2004, 1814-1816. (c) Xiao, J.C.; Shreeve, J. M. J. Org. Chem. 2005, 70, 3072-3080 and ref. cited therein.

(14) (a) Fukuyama, T.; Shinmen, M.; Nishitani, S; Sato, M. ; Ryu, I. Org. Lett. 2002, 4, 1691-1694. (b) Thathagar, M. B.; Kooyman, P. J.; Boerleider, R.; Jansen, E.; Eleevier, C. J.; Rothenberg, G. Adv. Synth. Catal. 2005, 347, 1965-1968.

(15)(a) Kaufmann, D. E.; Nouroozian, M.; Henze, H. Synlett 1996, 1091-1092. (b) Carmichael, A. J.; Earle, M. J.; Holbrey, J. D.; McCormac, P. B.; Seddon, K. R. Org. Lett. 1999, 1, 997-1000. (b) Böhm, V. P. W.; Herrmann, W. A. Chem. Eur. J. 2000, 6, 3209-3212. (c) Park, S. B.; Alper, H. Org. Lett. 2003, 5, 1691-1694. (d) Mo, J.; Xu, L.; Xiao, J. J. Am. Chem. Soc. 2005, 127, 751-760 and ref. cited therein.

(16) Zhao, D.; Fei, Z.; Geldbach, T. J.; Scopelliti, R.; Dyson, P. J. J. Am. Chem. Soc. 2004, 126, 1587615882.

(17)(a) Herrmann, W. A.; Brossmer, C.; Öfele, K.; Reisinger, C.-P.; Priermeier, T.; Beller, M.; Fischer, H. Angew. Chem. Int. Ed. Engl. 1995, 34, 1844-1848. (b) Herrmann, W. A.; Brossmer, C.; Öfele, K.; Beller, M.; Fischer, H. J. Mol. Catal. A 1995, 103, 133-146. 
(18) (a) Deshmukh, R. R.; Rajagopal, R.; Srinivasan, K. V.; Chem. Commun. 2001, 1544-1545. (b) Dupont, J.; Fonseca, G. S.; Umpierre, A. P.; Fichtner, P. F. P.; Teixeira, S. R. J. Am. Chem. Soc. 2002, 124, 42284229.

(19) Cassol, C. C.; Umpierre, A. P.; Machado, G.; Wolke, S. I.; Dupont, J. J. Am. Chem. Soc. 2005, 127, 3298-3299.

\section{Graphical Abstract:}

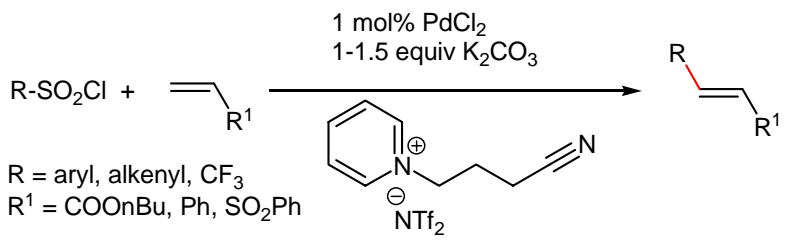

$140{ }^{\circ} \mathrm{C}, 1-2 \mathrm{~h}$

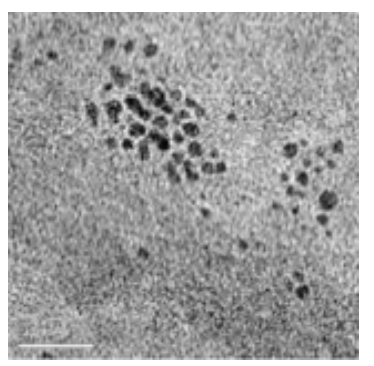

